\title{
Extraparotid Warthin Tumors Imitating Metastasis of Oral Cancers
}

\author{
Michał Gontarz ${ }^{10}$ Krzysztof Gąsiorowski ${ }^{10}$ Jakub Bargiel ${ }^{1(0)}$ Tomasz Marecik $^{10}$

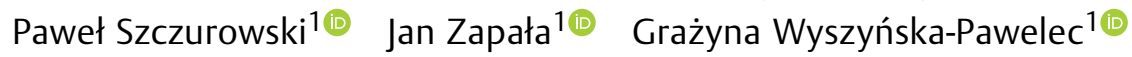 \\ ${ }^{1}$ Department of Cranio-Maxillofacial Surgery, Jagiellonian University \\ Medical College, Cracow, Poland \\ Address for correspondence Michał Gontarz, DDS, PhD, Assistant \\ Prof., Department of Cranio-Maxillofacial Surgery, Jagiellonian \\ Int Arch Otorhinolaryngol 2022;26(2):e278-e280. \\ University Medical College, University Hospital, 2 Jakubowskiego \\ Street, 30-688 Cracow, Poland (e-mail: mgontarz@op.pl).
}

\begin{abstract}
Introduction Extraparotid Warthin tumor (WT) is a very rare entity, especially when synchronous with oral cancer (OC).

\section{Keywords}

- Warthin tumor

- adenolymphoma

- squamous cell carcinoma

- mouth neoplasms

- head and neck squamous cell carcinoma

Objective The present study presents a case series of extraparotid WTs detected in the surgical specimen of patients treated for OC.

Methods From 2007 to 2016, 336 patients were operated for OC in our institution. Neck dissection was performed in 306 patients.

Results In the 306 patients operated for OC whose necks were dissected, unexpected WTs were observed in 4 surgical neck specimens. In 3 cases, extraparotid WTs were responsible for tumor, node, metastasis (TNM) overstaging before surgery.

Conclusion Extraparotid WTs may be discovered during neck dissection in $\sim 1 \%$ of OC patients, and they may mimic neck metastasis, especially in positron-emission tomography/computed tomography (PET/CT) imaging.
\end{abstract}

\section{Introduction}

Warthin tumor (WT) is the second most common salivary gland tumor, most commonly found in the tail of the parotid gland. ${ }^{1}$ The extraparotid localization of this tumor is uncommon and is observed up to $8 \%$ of all WTs. ${ }^{2}$ Warthin tumor can be observed in periparotid lymph nodes, especially at the first and second neck levels and may mimic metastasis in patients suffering from oral cancer (OC). ${ }^{3}$ Only a few case reports of synchronous WT and OC have been published in the English-language literature. ${ }^{3-5}$ This study presents a case series of extraparotid WTs detected in surgical specimen of patients treated for OC.

\section{Methods}

Between January 2007 and December 2016, 336 patients were operated due to OC in our institution. Neck dissection was performed in 306 patients, and, in 187 cases, neck dissection was bilateral. Unexpected WTs were observed in 4 surgical specimens. Two cases of synchronous parotid WT and squamous cell carcinoma of retroauricular region and two cases of metachronous parotid WT and OC were excluded from the study. Medical charts of the patients were evaluated retrospectively according to histopathological aspects and treatment. This study was approved by the institutional review board (No: 122.6120.287.2016).

\section{Result}

Four hundred and ninety-three neck dissection were performed in 306 patients, 184 of which were modifiedradical/radical neck dissections (MRND/RND) (37.5\%) and 309 of which were selective neck dissections (SND) (62.5\%). Extraparotid WTs were observed in the neck specimen of 4 received

October 15, 2020

accepted

December 13, 2020

published online

October 19, 2021
DOI https://doi.org/ 10.1055/s-0041-1724090. ISSN 1809-9777.

\footnotetext{
(c) 2021. Fundação Otorrinolaringologia. All rights reserved.

This is an open access article published by Thieme under the terms of the Creative Commons Attribution-NonDerivative-NonCommercial-License, permitting copying and reproduction so long as the original work is given appropriate credit. Contents may not be used for commercial purposes, or adapted, remixed, transformed or built upon. (https://creativecommons.org/ licenses/by-nc-nd/4.0/) Thieme Revinter Publicações Ltda., Rua do Matoso 170, Rio de Janeiro, RJ, CEP 20270-135, Brazil
} 
Table 1 Characteristics of patients with extraparotid Warthin tumor

\begin{tabular}{|l|l|l|l|l|l|l|l|l|l|}
\hline No & Age & Sex & Site of OC & cTNM & $\begin{array}{l}\text { Neck } \\
\text { dissection }\end{array}$ & Site of WT & pN & $\begin{array}{l}\text { Additional } \\
\text { treatment }\end{array}$ & $\begin{array}{l}\text { Follow-up } \\
\text { (months) }\end{array}$ \\
\hline 1 & 86 & $\mathrm{~F}$ & buccal mucosa & T3N1M0 & SOHND & Ila & N2b & PORT & 18 \\
\hline 2 & 67 & $\mathrm{~F}$ & tongue & T2N1M0 & MRND & Ila & N0 & No & 35 \\
\hline 3 & 65 & F & lower gingiva & T2N1M0 & SOHND & Ila & N0 & No & 28 \\
\hline 4 & 54 & M & FOM & T3N1M0 & SOHND & Ib & N0 & No & 46 \\
\hline
\end{tabular}

Abbreviations: cTNM, clinical tumor, node, metastasis stage; F, female; FOM, floor of mouth; M, male; MRND, modified radical neck dissection; OC, oral cancer; pN, pathologic node stage; PORT, postoperative radiotherapy; SOHND, supraomohyoid neck dissection; WT, Warthin tumor.

patients (1.3\%). All WTs were localized in ipsilateral neck specimen as the primary $O C$ focus. Warthin tumors were detected in 3 cases (75\%) at the Ila cervical lymph node level, and in 1 case $(25 \%)$ at the Ib level. Bilateral or multifocal extraparotid WTs were not observed. In 3 cases, extraparotid WTs were responsible for tumor, node, metastasis (TNM) overstaging before surgery. ( - Table $\mathbf{1}$ )

\section{Discussion}

Warthin tumors are the second most common benign salivary gland tumors after pleomorphic adenoma. ${ }^{6}$ The majority of WTs occur in the parotid gland. The multifocal and bilateral appearance of WTs might occur synchronously or metachronously. ${ }^{1}$ Extraparotid WTs are rare and sometimes multifocal. ${ }^{2}$ Most extraparotid WTs are located in the periparotid lymph nodes at the Ib, Ila, and III levels of the neck. The synchronous appearance of extraparotid WTs and OC is an extremely rare entity. In the English-language literature, there are only a few papers describing single-case reports. ${ }^{3,5}$ Only Sheanhan et al. ${ }^{4}$ presented one case of extraparotid WT $(0.5 \%)$ as an unexpected finding in neck dissection in 202 patients operated for head and neck squamous cell carcinoma. In the current study, extraparotid WTs in neck specimen were observed in 4 patients (1.3\%) with OC.

Microscopically, WTs comprise eosinophilic oncocytic double-layered epithelium lining the cyst lumen and hematoxyphilic lymphoid aggregates in the stroma. The epithelial and lymphatic components of WT are explained by two theories. The first one is that during embryogenesis, salivary elements might be trapped heterotopically within the extraparotid and parotid lymph nodes. ${ }^{7}$ This might explain why there is no evidence of WTs in the lower neck levels (IV and V). An alternative theory suggests that WT is not a neoplastic lesion but, most probably, it is caused by a delayed hypersensitivity reaction to degenerated oncocytes. ${ }^{7}$ The pathogenesis of WTs is still unclear. Some studies suggest that epithelial components and lymphocytic infiltrations are polyclonal, which may be evidence of the non-neoplastic nature of WTs. ${ }^{8,9}$ On the other hand, some WTs are characterized by a presence of at $(11 ; 19)$ translocation, similar to that of mucoepidermoid carcinoma. ${ }^{7}$ Such WTs are monoclonal and truly neoplastic and may lead to malignant transformation. But it is still unclear which factors trigger the development of WTs.
Smoking cigarettes has a strong association with WT development. ${ }^{1}$ In their study, Lewis et $\mathrm{al}^{10}{ }^{10}$ support that smoking cigarettes cause an oxidative damage of the mitochondrial DNA of oncocytic cell, which lead to the occurrence of WTs. Smokers have eight times higher risk of tumor development than non-smokers. ${ }^{10}$ Tobacco abuse is also one of the most important risk factors for OC. This might explain the coincidence of synchronous and metachronous WTs and OC.

A useful diagnostic tool for the staging and treatment planning of patients suffering from $O C$ is the 18 -fluorodeoxyglucose positron emission tomography (FDG-PET/CT). However, false positive FDG uptake is observed in inflammations and benign tumors. ${ }^{3,11}$ Warthin tumors are known to have high FDG uptake and, as such, might mislead to diagnosis of metastatic lymph nodes. Also, PET/CT is used relatively often in the follow-up of oncological patients. In this case, WT as an incidentaloma may be found in the tail of the parotid gland. ${ }^{11}$ In those cases, fine-needle aspiration cytology (FNAC) is recommended to confirm the diagnosis of WT. The diagnostic accuracy of FNAC for identifying WTs is good, ranging from 74 to $100 \%{ }^{12}$ According to the study by Schwalje et al., the growth rate of WTs is slow, especially in patient over 75 years old. ${ }^{13}$ For this reason, conservative management of WTs confidently diagnosed with FNAC is an option mainly for patients suffering from head and neck cancers treated with non-surgical modality.

\section{Conclusion}

Unexpected WTs may be discovered during neck dissection in $\sim 1 \%$ of OC patients Abnormal FDG uptake in PET/CT is typical for WTs, and it may suggest metastatic lymph node. For these reasons, the possibility of synchronous or metachronous WTs and OC should always be kept in mind by surgeons and radiotherapists, especially in patients with a history of WT.

Conflict of Interests

The authors declare that there is no conflict of interests.

\section{References}

1 Teymoortash A, Krasnewicz Y, Werner JA. Clinical features of cystadenolymphoma (Warthin's tumor) of the parotid gland: a retrospective comparative study of 96 cases. Oral Oncol 2006;42 (06):569-573. Doi: 10.1016/j.oraloncology.2005.10.017 
2 Patterson JW, WrightED, Camden S. Extraparotid Warthin's tumor.J Am Acad Dermatol 1999;40(03):468-470. Doi: 10.1016/s01909622(99)70499-8

3 Schwarz E, Hürlimann S, Soyka JD, Bortoluzzi L, Strobel K. FDGpositive Warthin's tumors in cervical lymph nodes mimicking metastases in tongue cancer staging with PET/CT. Otolaryngol Head Neck Surg 2009;140(01):134-135. Doi: 10.1016/j.otohns.2008.09.019

4 Sheahan P, Hafidh M, Toner M, Timon C. Unexpected findings in neck dissection for squamous cell carcinoma: incidence and implications. Head Neck 2005;27(01):28-35. Doi: 10.1002/hed.20110

5 Iwai T, Baba J, Shibasaki M, et al. 18F-fluorodeoxyglucose-positive Warthin tumor in a contralateral cervical lymph node mimicking metastasis in tongue cancer staging with PET/CT. J Craniofac Surg 2012;23(05):e507-e509. Doi: 10.1097/SCS.0b013e318266f750

6 Gao M, Hao Y, Huang MX, et al. Salivary gland tumours in a northern Chinese population: a 50-year retrospective study of 7190 cases. Int J Oral Maxillofac Surg 2017;46(03):343-349. Doi: 10.1016/j.ijom.2016.09.021

7 O'Neill ID. New insights into the nature of Warthin's tumour.J Oral Pathol Med 2009;38(01):145-149. Doi: 10.1111/j.1600-0714. 2008.00676.x
8 Honda K, Kashima K, Daa T, Yokoyama S, Nakayama I. Clonal analysis of the epithelial component of Warthin's tumor. Hum Pathol 2000;31(11):1377-1380

9 Takezawa K, Jackson C, Gnepp DR, King TC. Molecular characterization of Warthin tumor. Oral Surg Oral Med Oral Pathol Oral Radiol Endod 1998;85(05):569-575

10 Lewis PD, Baxter P, Paul Griffiths A, Parry JM, Skibinski DO. Detection of damage to the mitochondrial genome in the oncocytic cells of Warthin's tumour. J Pathol 2000;191(03):274-281

11 Lee SK, Rho BH, Won KS. Parotid incidentaloma identified by combined $18 \mathrm{~F}$-fluorodeoxyglucose whole-body positron emission tomography and computed tomography: findings at grayscale and power Doppler ultrasonography and ultrasound-guided fine-needle aspiration biopsy or core-needle biopsy. Eur Radiol 2009;19(09):2268-2274. Doi: 10.1007/s00330-009-1407-5

12 Vlantis AC, Ng SK, Mak CK, Cheung JM, Chan AB, van Hasselt CA. If cytology of Warthin tumor is accurate, can management be conservative? Ear Nose Throat J 2016;95(4-5):185-188

13 Schwalje AT, Uzelac A, Ryan WR. Growth rate characteristics of Warthin's tumours of the parotid gland. Int J Oral Maxillofac Surg 2015;44(12):1474-1479. Doi: 10.1016/j.ijom.2015.07.019 